\title{
Intellectualization of the Phased Assessment and Use of the Potential for Internationalizing the Activity of Clusters of Cultural and Creative Industries of the Baltic Sea Regions
}

\author{
Olha Prokopenko ${ }^{1}$, Vitaliy Omelyanenko ${ }^{2}$ \\ ${ }^{I}$ Tallinn University of Technology, 3 Akadeemia st., Tallinn, Estonia \\ ${ }^{2}$ Industrial Economics Institute of National Academy of Sciences of Ukraine, 2 Zhelyabova st., Kyiv, Ukraine
}

\begin{abstract}
The cultural and creative industries sector is an essential driving force of the Baltic Sea Region economy. This article presents a methodology for intellectualization, including phased assessment and use of the potential of internationalization of the clusters. It provides suitable templates of the estimation that can gradually improve the quality of the evaluation with the amount of available information. The methodology ensures transparency of the analysis and decision-making process. The presented methodology can be easily adapted to assess the potential of internationalized clusters in other sectors of the economy. Similarly, the potential of internationalization of cluster activities' concept is determined.
\end{abstract}

Keywords - Intellectualization of assessment, potential for internationalizing, clusters internationalizing, cultural and creative industries, Baltic Sea regions.

\section{Introduction}

The cultural and creative industries (CCI) sector, which includes a multitude of sub-sectors such as

DOI: 10.18421/TEM93-31

https://doi.org/10.18421/TEM93-31

Corresponding author: Olha Prokopenko,

Tallinn University of Technology, Tallinn, Estonia

Email: prokopenko.olha.w@gmail.com

Received: 11 April 2020.

Revised: 17 July 2020.

Accepted: 29 July 2020.

Published: 28 August 2020.

(cc)BY-NC-ND(C) 2020 Olha Prokopenko \& Vitaliy Omelyanenko; published by UIKTEN. This work is licensed under the Creative Commons AttributionNonCommercial-NoDerivs 4.0 License.

The article is published with Open Access at www.temjournal.com audiovisual industries, design, art, fashion, media, publishing, games and tourism, is an essential driving force of the Baltic Sea Region (BSR) economy. This has been recognized in the BSR Cooperation Program and in the Policy Area Culture of the EUSBSR Action Plan, both of which highlight the diverse and attractive cultural life of the BSR and the potential of its CCI sector to create (youth) employment and trigger innovative spillover effects in other areas.

Competitiveness and growth of the CCI of the BSR depend on how quickly and efficiently the activities of existing clusters (them support organizations and enterprises) can be internationalized, reinforcing each other due to the spread of new activities and their technologies in the $\mathrm{CCI}$, their promotion on the market, depending on how much will they be able to use modern business models for developing innovative products (services) that will at least improve the number of jobs and the quality of life in BSR, and how many at the maximum will be in demand all over the world, making BSR profit by selling licenses or direct services.

To make informed decisions on improving the competitiveness of the CCI sector, it is necessary to correctly assess the potential of clusters to transfer relevant experience, knowledge, and technology. The data on the activities of the CCI sector of the BSR are heterogeneous, which does not allow an accurate assessment of the potential of its internationalization. Not only is the availability of statistics different, but also the understanding of the CCI components in different BSRs. For decision-making on the internationalization of the activities of the CCI clusters of the BSR with a simultaneous increase in the accuracy of assessment and validity of decisions, it is necessary to create a methodology for the intellectualization of phased use and realization of the potential for internationalizing the activities of the CCI clusters of the BSR. 


\section{Formulation of the Problem of Assessment of the Potential of Internationalization the Activity of Clusters of the CCI Sector of the BSR}

Assessing the potential for internationalization of the CCI clusters of the BSR is a significant scientific and practical problem because it allows making decisions on choosing the most effective areas of internationalization for the CCI of the BSR.

At the same time, such an assessment is not simple due to the lack of comparable statistics and even an understanding of the CCI activities in different BSRs.

Experts of the Creative Ports project from Tallinn Technological University have found that the concept of the CCI and the list of elements (activities) included in it differ in different BSRs. An understanding of the components (sub-sectors) of CCI in Estonia, Germany, Finland, Denmark, Lithuania, Poland, Russia and Sweden (Latvia was not in the project) is different.

Apart from differences in understanding the CCI category and its structural elements, there is no single statistical basis for assessing the potential for internationalization of the CCI sector of the BSR. So, we have analyzed which sub-sectors belong to the CCI in eight countries of the BSR which are analyzed in this project.

The most significant number of sub-sectors are included in the CCI in Denmark. Like all countries of the BSR, Denmark includes to the CCI sector such subsectors as Architecture, Film, Video, Design, Theatre, Dance, Music, Publishing, Museums, Libraries, Visual Arts, Fine Arts, and Performing Arts. Denmark also includes Broadcasting, Fashion, Festivals, Handicraft, Interactive Entertainment, Advertising, Media Services, Tourism, Travel Agencies. Some countries include these sub-sectors, but some do not. Denmark only has as sub-sector Zoos / Botanical Gardens / Amusement parks. Only one more country, Finland, has as sub-sector Outdoor adventure services.

The authors realized that under the current conditions, for the prompt adoption of informed decisions on the internationalization of cluster activities, it is necessary to create an intelligent approach to the phased use of the potential, which includes business of CCI clusters of the BSR that would make it possible to make decisions already during the implementation of the project, without postponing them until the end of the project, increasing their validity with every iteration.

Thus, the accumulated data on the components of the potential would be processed by available methods, which will be replaced by more accurate ones upon receipt of clarifying information.

\section{The Concept of the Potential of Internationalization of the Activity of Clusters}

Even though the concept of potential is often used to describe and assess the development opportunities of an enterprise or country, increase competitiveness, etc., in literature, the authors did not find a concept of the potential of internationalization, and especially the potential for internationalizing the activity of clusters.

Recently, the potential of enterprises and organizations is investigated most often. So, the innovative aspects of managing the material and technical base and the formation of a management mechanism in managing the development of the potential of an industrial enterprise are investigated [1]. Modern Internet technologies that develop the potential of the enterprise are being studied. Even some of the psychological aspects of building the potential of an enterprise are being considered [2].

Much attention is paid to the study of individual components of the enterprise potential. The researchers studied the methods of assessing the innovative potential of enterprises. It has been established that the determination of a set of estimated indicators is central to the methodological support for evaluating the innovative potential of enterprises [3]. The concept of intellectual potential is proposed. The current state of its formation and use is analysed [4].

The main threats to the formation of personnel potential have been studied by personnel [5]. An approach to assessing scientific potential and recommendations for its increasing are proposed [6]. The definition of the organization's knowledge potential is given, and an integrated approach to its assessment is proposed [7].

The issues of the formation and development of various types of production potential within the enterprise, taking into account the changing economic conditions, as well as the impact of production potential on the actual activities of the enterprise are studied [8].

Study and evaluation of the competitiveness potential of the organizations in the construction industry is. The methodological approach to assessing the competitiveness potential of the organizations has been substantiated; this allows increasing the efficiency of managing the competitiveness process [9]. Approaches to the formation of the international competitive potential of an enterprise based on Industry 4.0 are proposed [10].

The concept of the transformative potential of an enterprise is proposed [11]. The essence of the innovative potential and its role in ensuring the competitiveness of the national economy in the 
conditions when technologies are rapidly changing are investigated [12]. The theoretical and methodological foundations for assessing, forming and using the export potential of enterprises have been improved [13]. The methodology for assessment and formation of strategic potential, economic potential and development potential of organizations has been substantiated [14].

At the same time, the national potential and regional development potential are also being investigated. A scientific and methodological approach to managing the export-import potential of the region has been developed [15]. It is proposed to evaluate the investment potential of territorial units, taking into account the factor "security of investment activity" (criminogenic, environmental, and political) [16]. The theoretical and methodological foundations of potential of economy socialization in the context of globalization are proposed [17].

Much attention is also paid to studying the potential of different industries. For example, it was proposed to develop the potential of tourism and hospitality based on the formation of automatic sales tunnels [18]. The directions for the formation of potential regarding the energy sector based on knowledge and technology transfer are proposed [19]. Prospects for the development of the potential of the market for glass materials in the field of glass recycling (with particular attention to the economic potential of the production of glass "triplex") are analysed [20].

Some aspects of the international potential of development are also being explored. For example, the potential for ordinary European politics has been investigated [21]. A classification of models for managing the export potential of the world's countries, based on the generalization of the experience of using state support for export instruments, is proposed [22].

The authors of the study [23] emphasize that innovation start-ups gain competitive advantages in narrow segments in international markets.

In studies [24], [25] is proved that the innovation regarding culture of the enterprise is a subsystem of its potential for development in different organizations. Therefore, we believe that issue of internationalization can be considered as an organizational factor of CCI development.

The authors took the liberty for the first time to define the potential of internationalization of clusters in the absence of its concept. Also cultural nature of such type of clusters requires another industrial sectoral approach [26], but innovation networks and internationalization methodology can also be applied [27].

The issue of CCI internationalization also requires regional-based analytics, i.e. considering it within the territories resources and territories development strategy [28].
Thus, the availability of the developed tools allows us to propose a methodology for determining strategic alternatives for the internationalization of cluster, which involves four stages of action:

1. Assessment of the level of internationalization of the industry to which the cluster belongs.

2. Assessment of the potential for internationalization of cluster members.

3. Assessment of the potential of internationalization of cluster as a system.

4. Selection of strategic directions of cluster internationalization.

5. Development of recommendations on the formation of strategic directions of cluster internationalization.

In our opinion, the potential for internationalizing the activities of ICI clusters can be defined as the opportunities for cluster's further development (expressed in new approaches, new activities, new technologies, resources, communications etc.) accumulated by the ICI sectors and their supporting organizations (supporting network), the transfer which leads to other clusters (through training, screenings, exhibitions, etc.) will give a positive result in the international development of the ICI sector.

\section{The Methodology of Assessment of the Potential of Internationalization of the Activity of CCI Clusters of the BSR}

Due to the lack of a methodology for assessing the potential for internationalizing the activity of clusters, the authors adopt the method of the least distances, which has an analytical and sometimes a graphical component.

This is one of the few methods for assessing potential that allows us to work with heterogeneous information by comparing various indicators of each cluster with the best indicators for the sector (in our case, indicators of each CCI cluster with the same best CCI indicators of the BSR sector).

Modification of the method of least distances to assess the potential of internationalization of clusters depending on the available data. The authors propose to calculate the integral assessment of the potential for internationalization of the activity of each CCI cluster within the BSR using the formula

$$
I_{j}=\sum_{i=1}^{n} W_{i} \cdot P_{i j},
$$

where $I_{j}$ - is integrated assessment of the potential for internationalization of the cluster $j(j €[1, m], m-$ number of clusters]), $W_{i}-$ indicator weight characteristic $i$ ( $i €[1, n], n$ - number of indicators], $\left.\sum_{i=1}^{n} W_{i}=1\right), P_{i j}$ is assessment of the potential for internationalization of cluster activity $j$ by the indicator $i$. 
At the same time, partial (calculated only on specific indicators) estimates of the potential for the internationalization of the CCI clusters of the BSR are proposed to be made using one of the formulas.

If a more significant indicator indicates a higher potential for internationalization (for example, the number of supporting organizations), then it is proposed to use the formula

$$
P_{j i}=\frac{I_{i j}}{I_{\text {imax }}}
$$

where $I_{i j}$ - is assessment of the internationalization potential of the cluster $j$ by the indicator $i, I_{i \max }-$ maximum value of indicator $i$ among all estimated clusters.

If a lower indicator value indicates a higher potential for internationalization (for example, tax and other barriers), then it is proposed to use the formula

$$
P_{j i}=\frac{I_{i \min }}{I_{i j}}
$$

where $I_{i \min }$ - is minimum value of the indicator $i$ among all estimated clusters.

By formula (1), the cluster has the highest internationalization potential if his integral estimate $I_{j}$ is the largest. Such an assessment allows us to rank clusters by the potential of internationalization.

However, this is not enough to make managerial decisions. It is necessary to analyze partial indicators of the potential for internationalization of clusters to understand what exactly the comparative advantage of each of them is.

A larger value of the private indicators $P_{i j}$ calculated according to formulas (2-3) characterizes a higher potential of cluster internationalization $\mathrm{j}$ in accordance with the indicator $i$.

It is high private indicators that indicate the best opportunities of a given cluster to transfer knowledge and technologies to other clusters.

Approaches to assessing the potential for cluster internationalization based on available data. Based on this and during the implementation of the Creative Ports project, experts from Tallinn University of Technology have identified seven the most significant indicators of the potential for the internationalization of the CCI clusters within the BSR, as well as determined their weight characteristics.

As already noted, the authors found that there is no uniform statistical information to assess the potential of the internationalization.

There are three situations for assessing the potential of cluster internationalization within each indicator:

A. Availability of comparable data for all clusters a situation of the possibility of quantifying high accuracy (A in Fig. 1).

B. The ability to quantify the indicator for some clusters (B1 in Fig. 1), but the inaccessibility of comparable data for other clusters (for example, due to the inclusion of additional data in the cluster assessment, which makes it possible to attribute data only to a certain interval, B2 in Fig. 1) - a situation of the possibility of quantifying a slightly lower accuracy due to the use of Interval Series.

C. The ability to perform only the Expert estimation due to the lack of sufficient comparable data $(\mathrm{C}$ in Fig. 1).

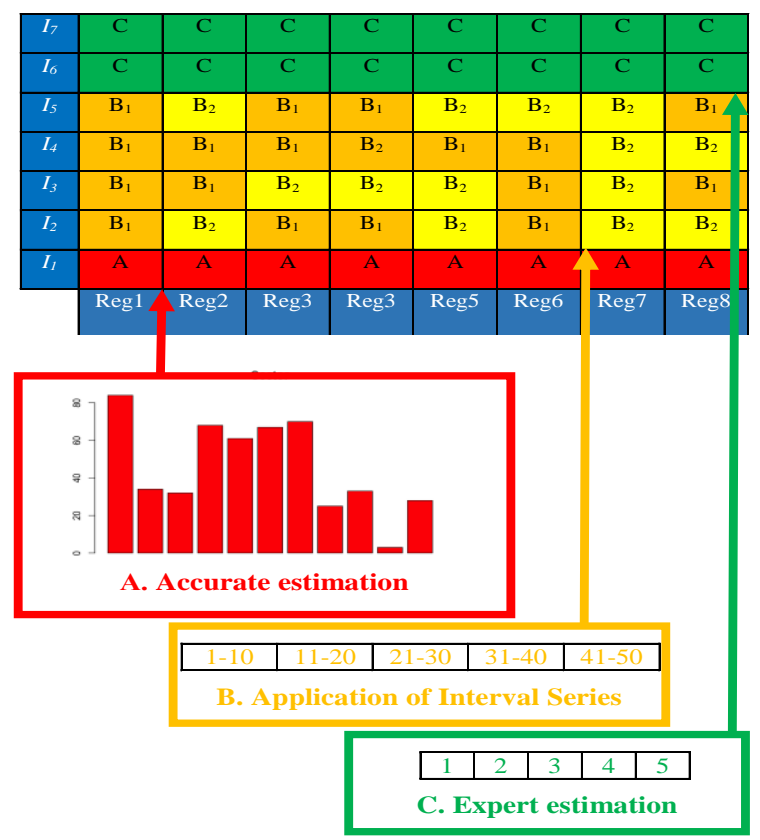

Figure 1. Possible approaches to assessing the potential of internationalization on the example of Estonia, Germany, Finland, Denmark, Lithuania, Poland, Russia and Sweden (author's development)

Thus, at the moment, it is possible to assess the potential for the internationalization of CCI of the BSR clusters with different accuracy depending on the available data. However, gradual data unification is expected.

Intellectualization of data collection and processing to obtain a more informed assessment of the potential and its phased use. Due to the gradual unification of data and the possibility of getting a more accurate assessment of the potential of internationalization of clusters and, accordingly, making more informed decisions on its use, the authors have identified the possibility of accumulation and computer processing of relevant information (Fig. 2, where $I_{i}=\left[I_{i 1} \ldots, I_{i \mathrm{~m}}\right]$ ).

Using this approach we create the possibilities to improve the database for assessment of the potential for internationalizing of clusters (Fig. 3).

Approbation the proposed method for assessing the potential of cluster internationalization. As the base for the statistical basis in order to assess the potential for internationalization of the CCI sector, we have considered the indicators of Global Innovation Index [29] for assessing the potential for CCI (Table 1). 


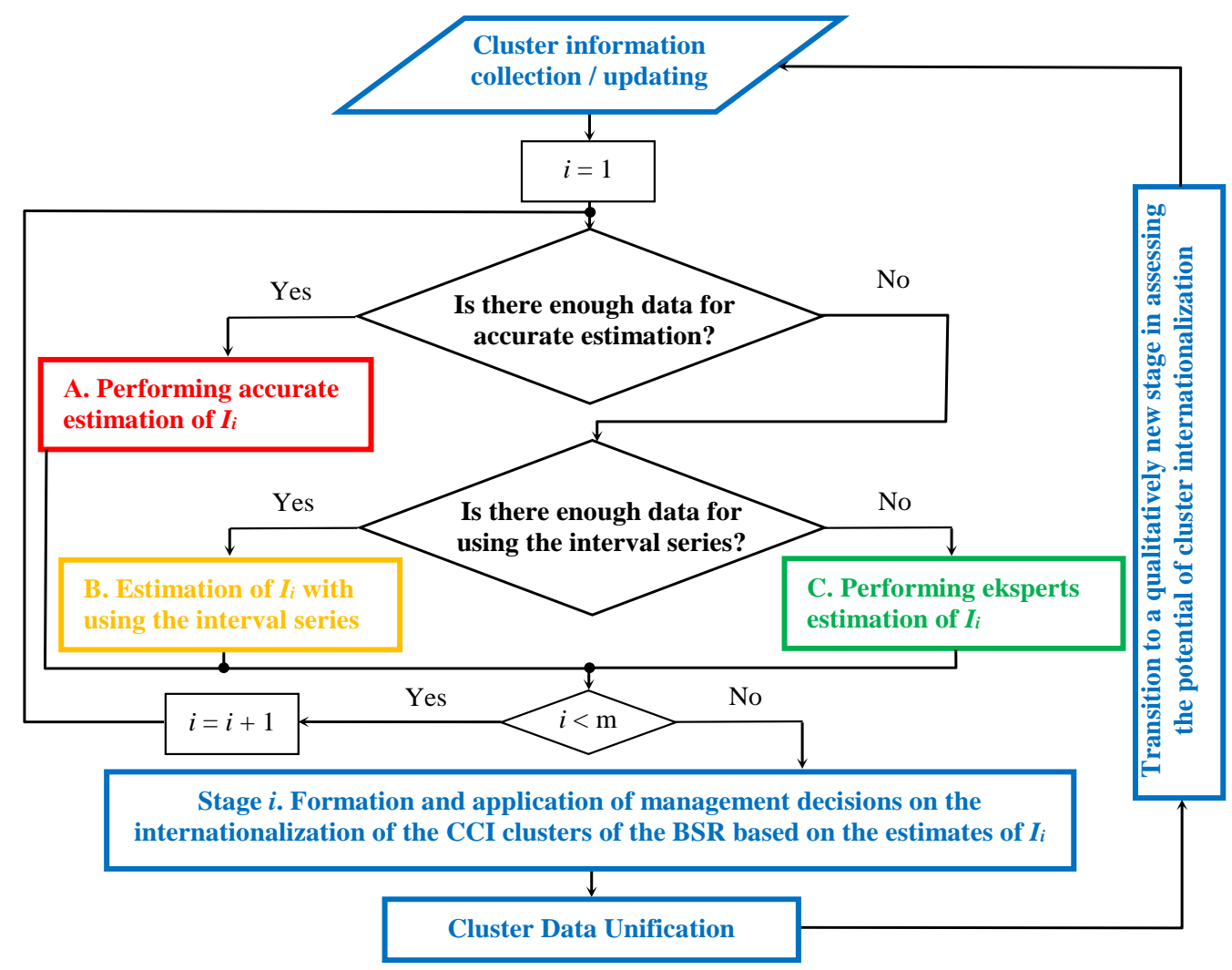

Figure 2. Intellectualization of the process of collecting and processing information for a phased assessment and realization of the potential of internationalization of clusters and its use

Fase 1

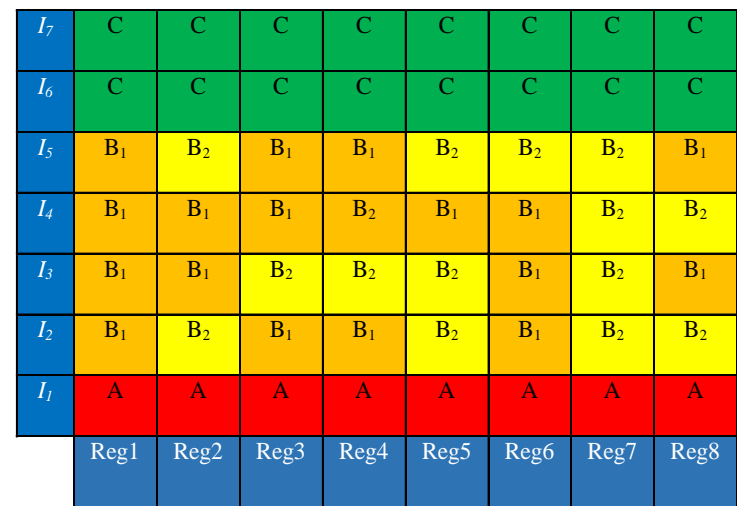

Fase 2

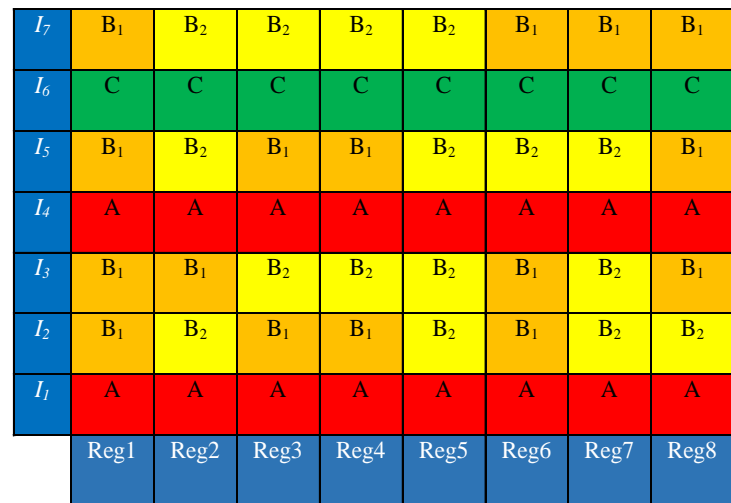

Fase 3

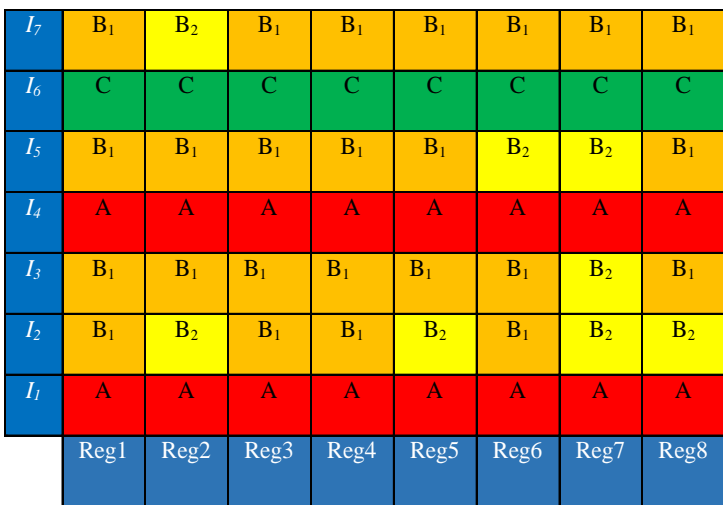

Fase m

$\vdots$

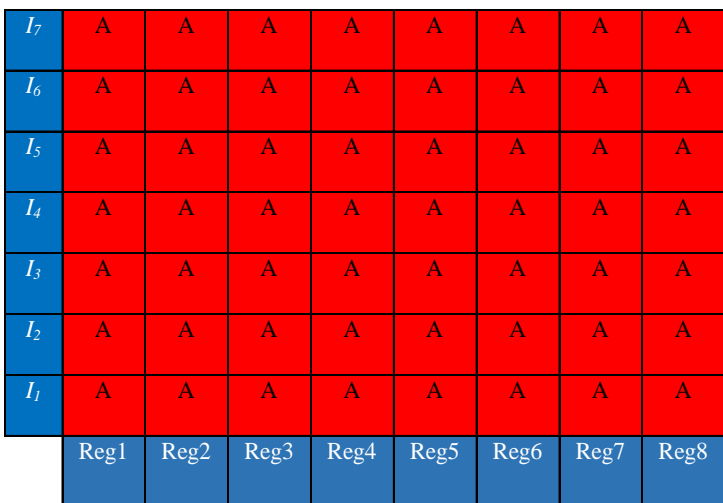

Figure 3. Improving the database for assessing the potential for internationalizing of clusters from phase to phase 
Table 1. Key indicators for assessing the potential for CCI (national level) based on the Global Innovation Index (2019)

\begin{tabular}{|c|c|c|c|c|c|c|c|c|c|c|}
\hline Indicator & 䄈 & $\frac{a}{\mathbb{1}}$ & 至 & 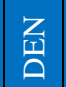 & ㄱ & 皀 & $\ddot{0}$ & $\stackrel{2}{2}$ & $\sum_{\infty}^{11}$ & $\geq$ \\
\hline $\begin{array}{l}\text { Cultural \& creative } \\
\text { services exports, \% } \\
\text { total trade }\end{array}$ & 1,6 & 0,9 & 1,0 & 0,6 & 1,5 & 0,6 & 1,1 & 1,0 & 11 & $\mathbf{0}, 2$ \\
\hline $\begin{array}{l}\text { National feature } \\
\text { films/mn pop. }\end{array}$ & 19.8 & 4,1 & 10,7 & 13,5 & 15,4 & 5,5 & 1,8 & 1,2 & 10.1 & 0,1 \\
\hline $\begin{array}{l}\text { Printing \& other } \\
\text { media, \% } \\
\text { manufacturing }\end{array}$ & 2,1 & 1 & 11 & 1 & 2,8 & 1,2 & 1,2 & 0,8 & 1,2 & 0,1 \\
\hline $\begin{array}{l}\text { Creative goods } \\
\text { exports, \% total } \\
\text { trade }\end{array}$ & 1,4 & 2,2 & 0,5 & 1,6 & 3,1 & 2,0 & 4,4 & 0,3 & 1,8 & 0,2 \\
\hline $\begin{array}{l}\text { State of cluster } \\
\text { development }\end{array}$ & & & 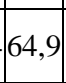 & 63,9 & 46 & & & 41 & 67, & \\
\hline
\end{tabular}

According to formula 1 we have estimated the potential for internationalizing of CCI sector development in BSR at the national level (Fig. 4).

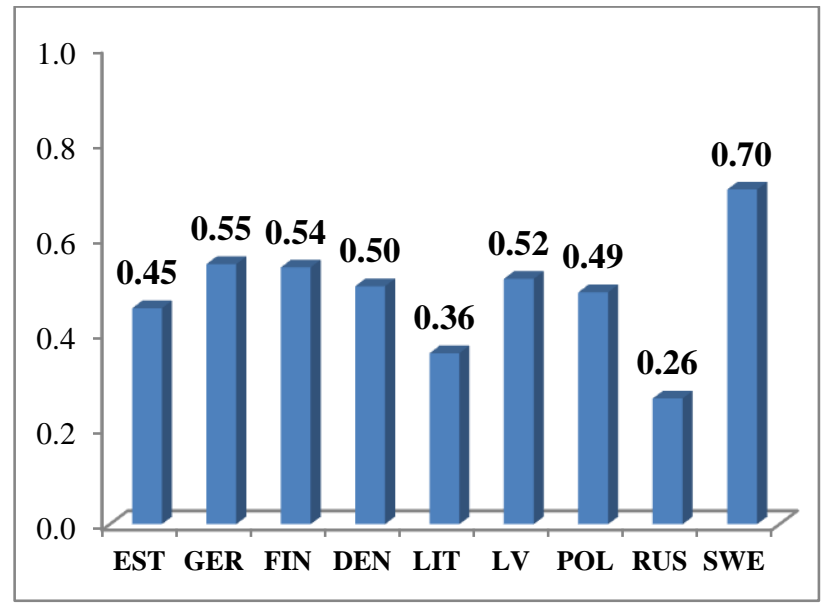

Figure 4. Potential for internationalization of the CCI sector in the BSR

Detailed (partial, calculated on specific indicators) estimation the potential for internationalizing of CCI clusters development according to formula 2 and 3 one can see on Fig. 5 - Fig. 13 (to improve visibility, it is possible also to change the angles of the cycloramas depending on the weight characteristics of the indicators).

In our opinion, the given indicators can be some general background for CCI sector national development estimations, but as it was shown in point 2 of this research, different understanding of the CCI elements in different countries and different regions requires more detailed analysis.

However, the achievement of objective estimates the potential for internationalization the activity of clusters of CCI industries within the BSRs requires the correct choice of a system of indicators, which has not yet been formed.

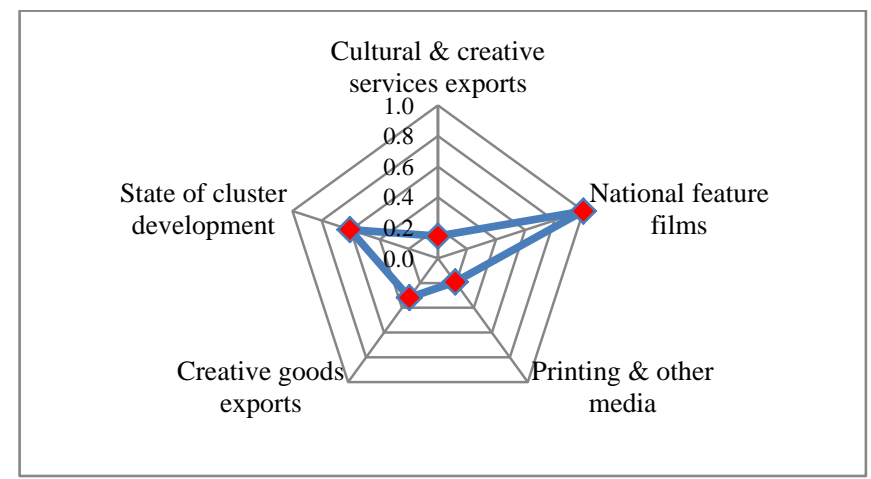

Figure 5. Potential for internationalization of the CCI sector (EST)

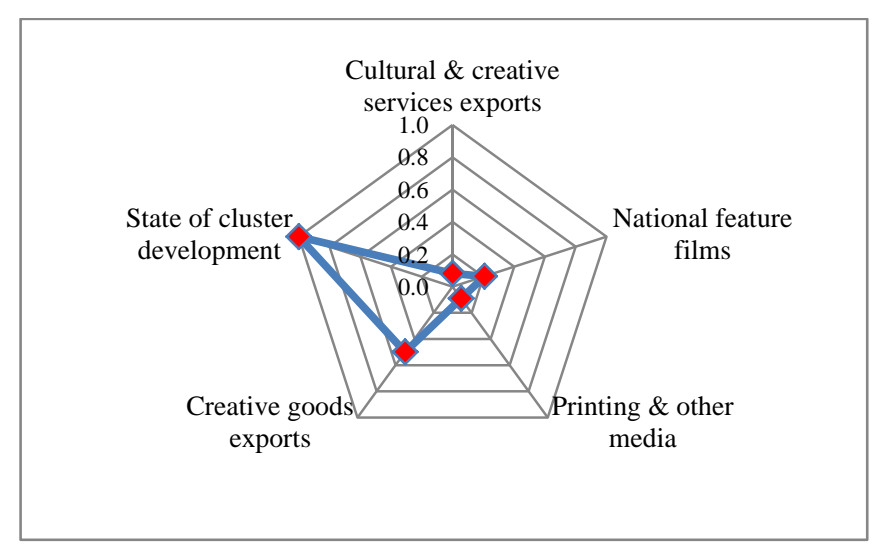

Figure 6. Potential for internationalization of the CCI $\operatorname{sector}(G E R)$

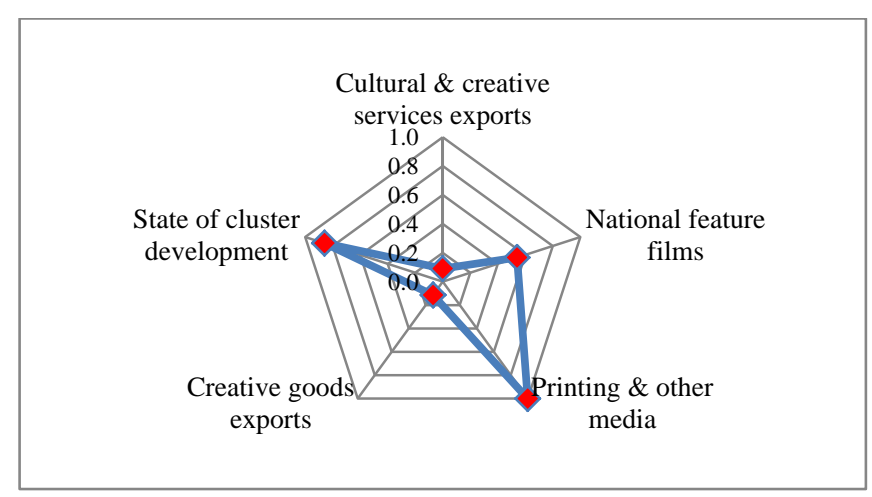

Figure 7. Potential for internationalization of the CCI sector (FIN)

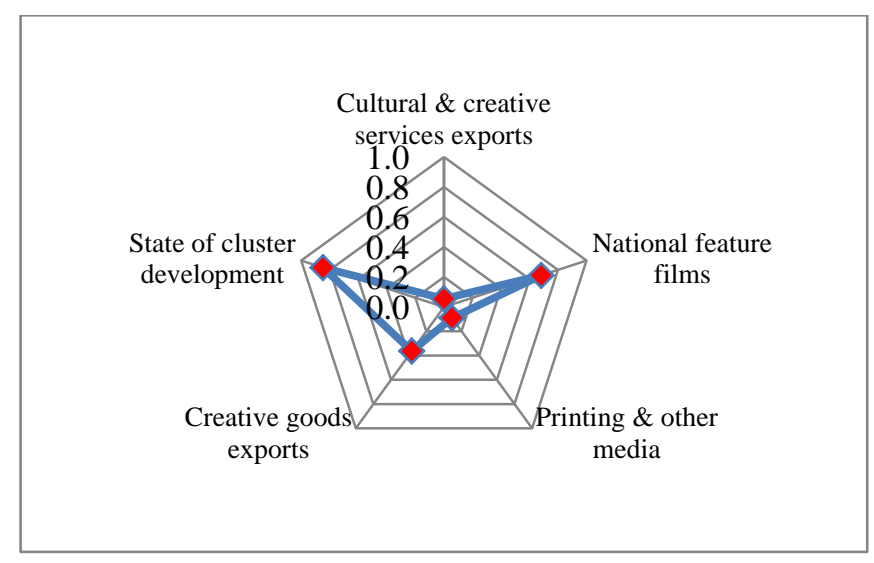

Figure 8. Potential for internationalization of the CCI sector (DEN) 


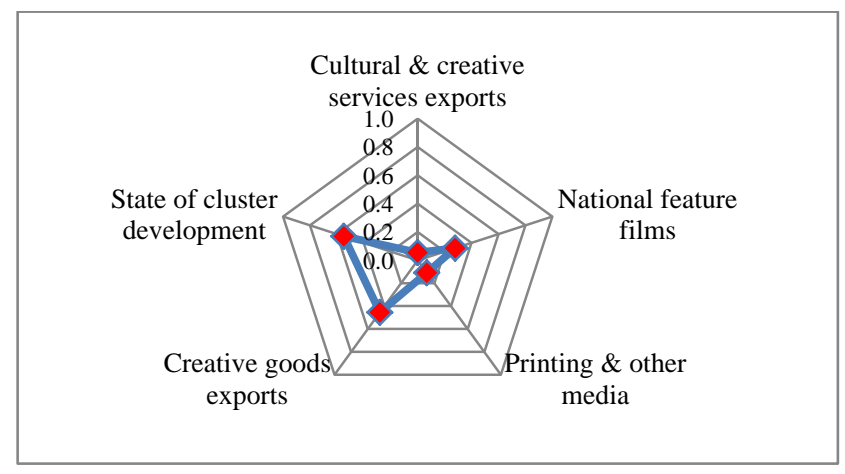

Figure 9. Potential for internationalization of the CCI sector (LIT)



Figure 10. Potential for internationalization of the CCI sector $(L V)$

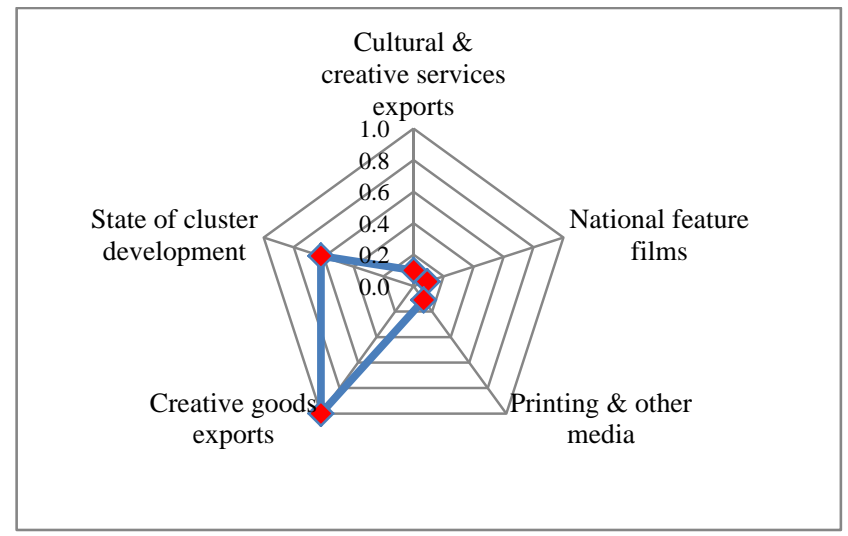

Figure 11. Potential for internationalization of the CCI clusters $(P O L)$

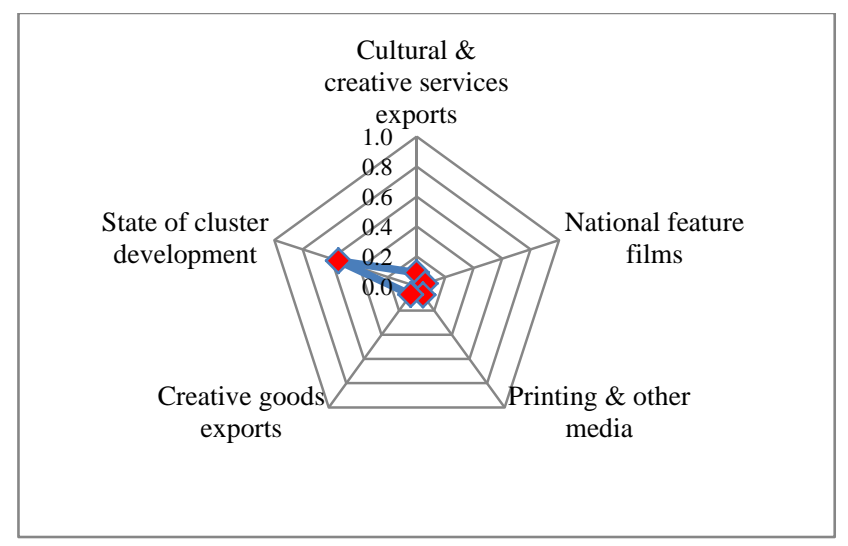

Figure 12. Potential for internationalization of the CCI sector (RUS)

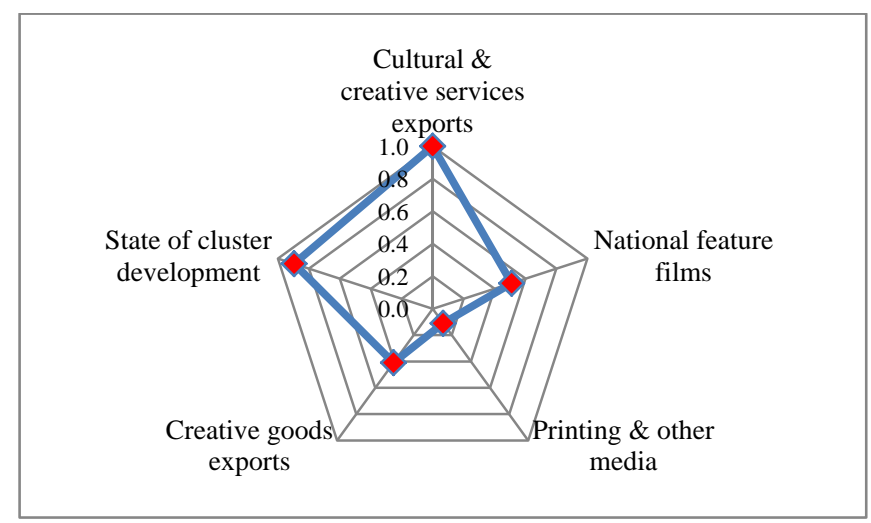

Figure 13. Potential for internationalization of the CCI clusters (SWE)

Decision making based on research results. The proposed methodology allows to:

- rank clusters by internationalization potential;

- compare clusters for specific internationalization opportunities;

- disclose information about cluster capabilities for organizations of the ICC sector;

- make management decisions on the internationalization of the activities of the ICC sector of the BSR;

- increase the accuracy of assessing the potential for internationalization of clusters.

\section{Conclusion}

This article presents a convenient methodology for intellectualization a phased assessment and use of the potential of internationalization of the CCI clusters of the BSR. The methodology provides suitable templates of the estimation that can gradually improve the quality of the estimation with the amount of available information. The methodology ensures transparency, of the analysis and decisionmaking process. Also, the internationalization of cluster activities' sense is determined.

In the future, the authors intend to study in detail the instruments for internationalizing the activity of clusters (some intentions can be seen in [30]).

\section{Acknowledgements}

The research used some results of the $E U$ project "Internationalization of the Cultural and Creative Industries in the Baltic Sea Region (Creative Ports)" funded by INTERREG programme and supported by Academic Studies of Estonian Language and Culture Abroad (EKKAV) program of Archimedes Foundation (Estonia). 


\section{References}

[1]. Voronkova, O. V., Kurochkina, A. A., Firova, I. P., \& Yaluner, E. V. (2016). Innovative managerial aspects of the potential of material-technical base and the formation of controlling mechanism in the management of the enterprise potential development. The Journal of Internet Banking and Commerce, 21 (6), 14p.

[2]. Terek, E., Nikolic, M., Cocallo, D., Bozic, S., \& Nastasic, A. (2017). Enterprise Potential, Entrepreneurial Intentions and Envy. Central European Business Review , 6 (2), 30-41.

[3]. Nikolskaya, E. Y., Lepeshkin, V. A., Kulgachev, I. P., Popov, L. A., Romanova, M. M., \& Lebedev, K. A. (2018). Methodological approaches to assessing the innovative potential of enterprises in the hotel business. Revista ESPACIOS, 39(27).

[4]. Kungurtseva, G. F. (2014). Intellectual potentials of a social organization: problems of development and utilization. Sociological Studies, 9(9), 63-68.

[5]. Romanov, E. V. (2018). Threats to the personnel potential of regional universities. Economy of the region, 14(1), 95-108.

[6]. Petrashenko, P. R., \& Iel'chyts, T. V. (2004). Scientific potential of the higher educational institutions of the Ministry of Health of Ukraine. Likars' ka sprava, (3-4), 3-15.

[7]. Raudeliūnienè, J., \& Szarucki, M. (2019). An Integrated Approach to Assessing an Organization's Knowledge Potential. Engineering Economics, 30(1), 69-80.

[8]. Kuzmenko, L. V. (2015). Production Potential Formation At An Agricultural Enterprise. Aktual'ni Problemy Ekonomiky = Actual Problems in Economics, (164), 205.

[9]. Polovnikova, N. A., Chepachenko, N. V., \& Yudenko, M. N. (2018). Study and Evaluation of the Competitiveness Potential of the Organizations in the Construction Industry. In Materials Science Forum (Vol. 931, pp. 1178-1181). Trans Tech Publications Ltd.

[10]. Dzwigol, H., Dzwigol-Barosz, M., \& Kwilinski, A. (2020). Formation of Global Competitive Enterprise Environment Based on Industry 4.0 Concept. International Journal of Entrepreneurship, 24(1), 1-5.

[11]. Wagenaar, H., Healey, P., Laino, G., Healey, P., Vigar, G., Riutort Isern, S., ... \& Wagenaar, H. (2015). The transformative potential of civic enterprise. Planning Theory \& Practice, 16(4), 557585.

[12]. Lomachynska, I., \& Podgorna, I. (2018). Innovation potential: impact on the national economy's competitiveness of the EU developed countries. Baltic Journal of Economic Studies, 4(1), 262-270.

[13]. Tyurina, N. M., Shelest, Y. O., Karvatska, N. S., \& Nazarchuk, T. V. (2017). Development of the export potential of industrial enterprises. Naukovij visnik Nacional'nogo girničogo universitetu, (1), 143-152.

[14]. Prizhigalinskaya, T. N., Ternovsky, D. S., Lyubov'V, U., \& Marina, G. (2015). Strategic Potential and Potential of Consumer Cooperation Organizations' Development: Methodology of Formation and Assessment. Journal of Internet Banking and Commerce, 20(S1).
[15].Gryshchenko, V. F., Dreval, O. Y., \& Gryshchenko, I. V. (2015). Regional Export-Import Potential Use Management Within The System of Ecological and Economic Security. Aktual'ni Problemy Ekonomiky= Actual Problems in Economics, (170), 226.

[16]. Dzwigol, H., Aleinikova, O., Umanska, Y., Shmygol, N., \& Pushak, Y. (2019). An entrepreneurship model for assessing the investment attractiveness of regions. Journal of Entrepreneurship Education, 22, 17.

[17]. Sardak, S., Bilskaya, O., \& Simakhova, A. (2017). Potential of economy socialisation in the context of globalisation. Economic Annals-XXI, 164 (3-4), 4-8.

[18]. Bashynska, I., Lytovchenko, I., \& Kharenko, D. (2019). Sales tunnels in messengers as new technologies for effective Internet-marketing in tourism and hospitality. International Journal of Innovative Technology and Exploring Engineering, 8(12), 594-598.

[19]. Miśkiewicz, R. (2018). The importance of knowledge transfer on the energy market. Polityka Energetyczna, 21.

[20]. Prokopenko, O., Mehovich, S., \& Romanyuk, Ya. (2019). Strategic Prospects for the Development of Glass Products Market and the Field of Glass Recycling in Ukraine. International Journal of Ecological Economics and Statistics, 40 (4).

[21]. Blings, S., \& Gattig, A. (2019). Exploring the potential for common European politics: crossnational commonalities and differences in the European constitutional referendums. Journal of European Integration, 41(6), 711-728.

[22]. Chychkalo-Kondratska, I., \& Radchenko, L. (2013). The Analysis of the Export Potential Management Models Of The World's Countries. Economic AnnalsXXI, 5-6 (1), 7-10.

[23]. Oviatt, B. M., \& McDougall, P. P. (1995). Global start-ups: Entrepreneurs on a worldwide stage. Academy of Management Perspectives, 9(2), 30-43.

[24]. Iliashenko, S.M., \& Shipulina, Y.S. (2014). Factor analysis of the state of innovative culture of the enterprise. Economic Annals-XXI, № 3-4, pp. 31-34.

[25]. Omelyanenko, V., Semenets-Orlova, I., Khomeriki, O., Lyasota, L., \& Medviedieva, Y. (2018). Technology transfer management culture (educationbased approach). Problems and perspectives in management, (16, Iss. 3), 454-463.

[26]. Marekha, I., \& Omelyanenko, V. (2016). Cultural aspect of innovation strategies' ecologization. Economic annals-XXI, (162), 9-12.

[27]. Prokopenko, O. V., Omelianenko, V. A., \& Eremenko, Y. I. (2014). Role of international factor in innovation ecosystem formation.

[28]. Kookueva, V., \& Tsertseil, Ju. (2019). Formation of Innovation Clusters as a Basis for the Development Strategy of Russia's Territories. International journal of scientific \& technology research, 8(9), 1733-1743.

[29]. World Intellectual Property Organization, Cornell University, \& INSEAD. (2019). The Global Innovation Index 2019: Creating Healthy Lives-The Future of Medical Innovation. World Intellectual Property Organization.

[30]. Prause, G., Feuerhake, C., Hochheim, H., \& Hunke, K. (2012). Trade Fair Participation as Internationalisation and Networking Instrument for SME. In Conference Proceedings of the International Entrepreneurship Forum (Vol. 2, pp. 874-889). 